\title{
The Effects of Entrepreneurship and Entrepreneurial Intention on Expected Outcomes of Startup: Moderated Mediation Effect of Growth Mindset
}

\author{
Chang Seek Lee ${ }^{1}$, Eun Kyung Ryu ${ }^{2} \&$ Ha Young Jang ${ }^{2}$ \\ ${ }^{1}$ Dept. of Health, Counseling and Welfare, Hanseo University, South Korea \\ ${ }^{2}$ Dept. of Child and Adolescent Counseling and Psychology, Hanseo University, South Korea \\ Correspondence: Ha Young Jang, Dept. of Child and Adolescent Counseling and Psychology, Hanseo University, \\ 31962, South Korea. Tel: 82-10-9400-9544. E-mail: besof@ hanmail.net
}

Received: April 9, 2020

Accepted: May 9, 2020

Online Published: May 23, 2020

doi:10.5430/rwe.v11n2p105

URL: https://doi.org/10.5430/rwe.v11n2p105

\begin{abstract}
Background/Objectives: The purpose of this study was to identify the moderating effects of the growth mindset on the mediating effects of entrepreneurial intention between the entrepreneurship and the expected outcomes of startup.

Methods/Statistical analysis: A survey was conducted on 280 employees from H and D cities in Korea. Frequency analysis and correlation analysis were performed for this study. Finally, regression analysis was conducted to analyze the moderated mediation effects.

Findings: The main findings were as follows. As a result of correlation analysis, a positive correlation was observed between all the major variables. The growth mindset had a moderating effect on the mediating effect of the entrepreneurial intention between the entrepreneurship and the expected outcomes of startup.

Improvements/Applications: Based on the results of this study, we discussed ways to improve the outcome of start-up using entrepreneurship and growth mindset.
\end{abstract}

Keywords: entrepreneurship, entrepreneurial intention, expected outcomes of startup, growth mindset, moderated mediation effect

\section{Introduction}

Entrepreneurship is indicated as creating a new type of organization by executing a new merger of the organization, producing raw materials in new ways, and discovering new markets (Schumpeter, 1934). The word entrepreneurship is derived from the term 'entrepreneur's spirit' and is used in the same sense, however, it is necessary to be distinguished according to the times as it gives bias to the actor. With the advancing development in information and communication technologies such as the internet, mobile business, and diversity of converged and mixed contents, the Fourth Industrial Revolution has led to startups that are not limited to the field. Due to the growing interest in start-ups for job creation and economic growth, entrepreneurship has expanded to various fields such as sociology, history, business administration, psychology as well as business administration.

Entrepreneurship focuses on the psychological factors that are the base of the entrepreneurship, along with competencies that are divided into skills, knowledge, and attitudes.

Entrepreneurship is based on a growth mindset to create value in limited circumstances and to seek opportunities and places no limits on one's ability (Ley and Timmons, 2013). Growth mindset is a system of belief in one's abilities (Molden and Dweck, 2006), and is constantly challenging towards their goals and tend to be achievement oriented. Entrepreneurs overcome the fear of failure, accept failure as a challenge, and draw new attempts through it (Drucker, 2014). They also lead in developing new products and embracing opportunities and changes through innovative activities. These psychological factors pursue an innovative entrepreneurship that is progressive and takes risks and challenges. However, start-ups are still uncertain and are difficult to access due to the lean possibility of success. Despite the favorable policies and environment for start-ups, actual difficulties and losses caused by failures are causing hesitation. However, various previous studies have shown that growth mindset is a driving force based on entrepreneurship and has a positive effect on entrepreneurial intention (Lumpkin and Dess, 1996). 
Starting a business is the first step in establishing a new organization, which means the psychological state that understands the business process and wants to do entrepreneurial behavior (Krueger et al., 2000). Fear of recent failures tends to favor low-risk occupations, suggesting that individual's risk-taking is a factor of entrepreneurship that can have a big impact on entrepreneurial intention i.e., when considering to start a business, one's own willingness to carry out business is very important, and one must have a strong belief in starting a business. In addition, the expectation and motivation to be successful in the process of selecting a business are essential.

Entrepreneurs have a high expectation of earning a higher income and have a higher quality of life compared to public officials who choose stable jobs. Thus, high expectations for start-up are closely related to entrepreneurial intention. Entrepreneurs have a strong influence on the psychological values of achievement, self-esteem, growth mindset, economic benefits and risk-taking tendency after start-up, compared to general workers (Covin and Slevin, 1991). Expected outcomes of startup may be be elevated through entrepreneurial intention, however, there is a lack of research on the influence between personal characteristics and factors affecting the startup process.

Therefore, this study investigated the mediating effect of entrepreneurial intention in the relationship between entrepreneurship and expected outcomes of startup, identified the moderating effects of growth mindset on the relationship between entrepreneurship and entrepreneurial intention, and finally identified the moderating effects of the growth mindset on the mediating effects of entrepreneurial intention between the entrepreneurship and the expected outcomes of startup (Johar et al., 2017); (Junwen et al., 2019).

The following research questions were established.

Are there any differences in expected outcomes of startups according to personal characteristics?

Is there a correlation between the main variables?

Does the growth mindset of workers moderate the mediating effect of entrepreneurial intention in the relationship between entrepreneurship and expected outcomes of startup?

\section{Methods}

\subsection{Research Model}

Under the research purpose of analyzing this study, the following research model was set as shown in Figure 1.

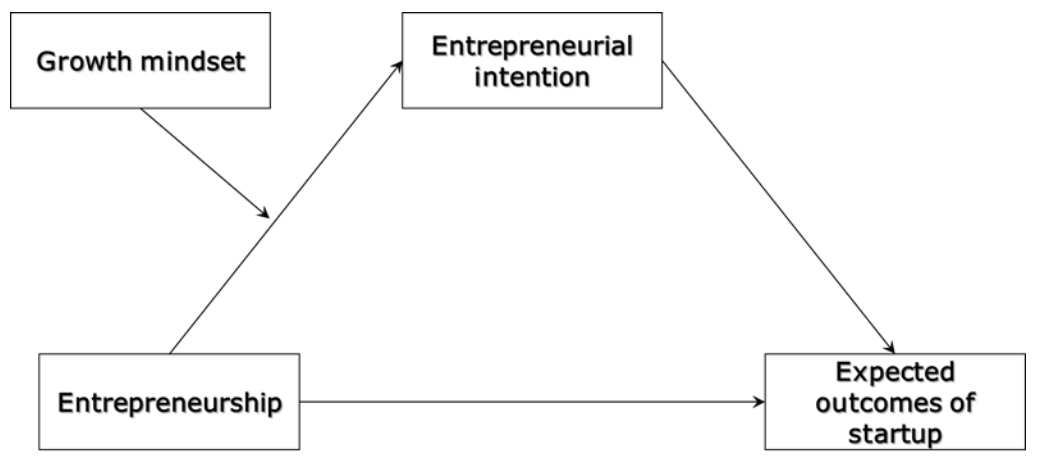

Figure 1. Research model

\subsection{Research Subjects}

The subjects of this study were 280 employees who worked in H and D city, Chungcheongnam province. A survey was conducted on the subjects from November 2019 to December 2019. A total of 254 copies were used for the final analysis, excluding 26 questionnaires that were unfaithfully answered.

The gender distribution of the study subjects was 212 males (83.5\%) and 37 females (14.6\%). The age distribution among subjects were as follows: $23.6 \%$ were in their $60 \mathrm{~s}, 45.3 \%$ in their $30 \mathrm{~s}, 20.9 \%$ in their $40 \mathrm{~s}$, and $8.7 \%$ in their $50 \mathrm{~s}$. Based on the marital status, 120 women $(47.2 \%)$ were married and 128 women $(50.4 \%)$ were not married. The distribution of working years was $131(51.6 \%)$ for less than 5 years, 52 (20.5\%) for less than 10 years, $35(13.8 \%)$ for less than 15 years, and $31(12.2 \%)$ for more than 15 years.

Based on their professional status, there were 112 employees (44.1\%), 51 assistant managers (20.1\%), 44 section 
chiefs (17.3\%), and 38 superintendents (15.0\%).

\subsection{Research Tools}

\subsubsection{Entrepreneurship}

We used entrepreneurship scale developed by Kim (2016) and modified and reconstructed by Kim (2018). This scale is divided into three subfactors: innovativeness, progressiveness and risk-sensitiveness each with 4 questions, forming 12 questions in total. Each item was measured on a five-point Likert scale, ranging from 1 point for "not at all" to 5 for "very so". Higher scores mean higher entrepreneurship. In this study, Cronbach's $\alpha$ was .904.

\subsubsection{Growth Mindset}

Growth mindset was used in this study based on the scale developed by Dweck (2006). The scale was divided into two subfactors; intelligence and personality with 4 questions each. Each item was measured on a five-point Likert scale, ranging from one point for "not at all" to five points for "very so". The higher the score, the higher the growth mindset. According to the analysis, Cronbach's $\alpha$ of growth mindset on intelligence was .702, and Cronbach's $\alpha$ of growth mindset on personality was 649 .

\subsubsection{Entrepreneurial Intention}

We used the entrepreneurial intention scale reconstructed by Heo (2018) based on Crant's research (1996). The scale consists of five questions: future vision, business operation plan, start-up market, situation planning, and future start-up plan. Each item was measured on a five-point Likert scale, ranging from one point for "not at all" to five points for "very so". Higher scores mean higher entrepreneurial intention. According to the analysis, the reliability Cronbach's $\alpha$ was .805 .

\subsubsection{Expected Outcomes of Startup}

Expected outcomes of startup based on the measures of Kang (2012) and Jang (2018) was used. The scale consists of five items: self-efficacy, status, expectations of profit, and expectations of regional development. Each item was measured on a five-point Likert scales, ranging from one point for "not at all" to five points for "very so", and the higher the score, the higher the expected outcomes of startup. The reliability of this scale, Cronbach 's $\alpha$, is .798.

\subsubsection{General Characteristics}

The gender, age, marital status, years of service and occupational status of the study subjects were examined.

\subsection{Data Analysis}

Collected data were analyzed using SPSS Win 23.0 and SPSS PROCESS Macro. Correlation analysis was conducted to identify the correlations among the major variables used in the study. Moderated mediation effect analysis was performed by applying Model 7 of the SPSS PROCESS Macro proposed by Hayes.

\section{Results and Discussion}

\subsection{Correlation of Main Variables}

The correlation analysis results among the major variables were as shown in Table 1. According to the results, a positive correlation was observed between all variables. Among these, entrepreneurial intention and expected outcomes of startup showed the highest correlation $(\mathrm{r}=.490, \mathrm{p}<.01)$, followed by growth mindset related to intelligence and growth mindset related to personality $(\mathrm{r}=.435, \mathrm{p}<.01)$, followed by entrepreneurship and expected outcomes of startup $(\mathrm{r}=.433, \mathrm{p}<.01)$. The range of each correlation coefficient for all variables was .041 to .490.In addition, there was no multicollinearity between variables.

Table 1. Correlation coefficients between major variables

\begin{tabular}{lccccc}
\hline \multicolumn{1}{c}{1.} & 2. & 3. & 4. & 5. \\
\hline 1. Entrepreneurship & 1 & & & & \\
\hline 2. Growth Mindset - Intelligence & .048 & 1 & & \\
\hline 3. Growth Mindset - Personality & $.190^{* *}$ & $.435^{* *}$ & 1 & 1 \\
\hline 4. Entrepreneurial Intention & $.388^{* *}$ & $.178^{* *}$ & $.167^{* *}$ & \\
\hline
\end{tabular}




\begin{tabular}{cccccc}
\hline 5. Expected Outcomes of Startup & $.433^{* *}$ & .058 & .041 & $.490^{* *}$ & 1 \\
\hline Mean & 3.27 & 3.27 & 3.11 & 3.26 & 3.24 \\
\hline Standard Deviation & .54 & .67 & .61 & .64 & .61 \\
\hline $\mathrm{p}<.01$ & & & &
\end{tabular}

\subsection{The Moderated Mediating Effects of Growth Mindset on the Relationship Between Entrepreneurship and Expected Outcomes of Startup Through Entrepreneurial Intention}

The results of the moderated mediation effect of the growth mindsetare presented in Figure 2 and Table 2.

According to the analysis results, entrepreneurship had a significant positive effect on entrepreneurial intention (.4367, $\mathrm{p}<.001)$, and entrepreneurial intention had a significant positive effect on expected outcomes of startup (.3576, $\mathrm{p}<.001)$. Based on this, entrepreneurial intention plays a mediating role between entrepreneurship and expected outcomes of startup. This is consistent with the finding that people with high entrepreneurship have high entrepreneurial intention, and entrepreneurship have a positive effect on achieving high expected outcomes of startup (Spencer and Spencer, 2008).

In addition, the interaction term of entrepreneurship and Personality had a significant effect on entrepreneurial intention (.2010, $\mathrm{p}<.05)$. Thus, entrepreneurship has a significant relationship to increase expected outcomes of startup through entrepreneurial intention, which means that the effect depends on growth mindset on the personality, which is a moderating variable.

On the other hand, the interaction term of entrepreneurship and growth mindset on intelligence did not have a significant effect on entrepreneurial intention.

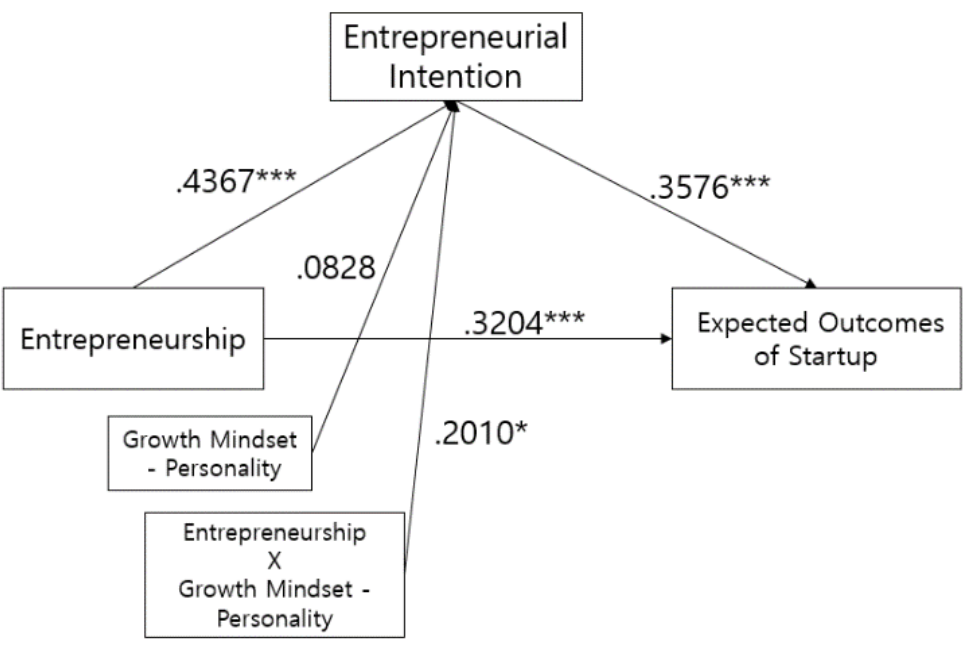

Figure 2. Statistical model of moderated mediation effect

Table 2. Conditional effects of growth mindset

\begin{tabular}{ccccc}
\hline Variables & Effect & SE & t-value & $\mathrm{p}$ \\
\hline Mediating variable model (dependent variable: entrepreneurial intention) & \\
\hline Constant & 3.2505 & .0377 & 86.1234 & .0000 \\
\hline Entrepreneurship & .4367 & .0695 & 6.2819 & .0000 \\
\hline Growth mindset - personality & .0828 & .0628 & 1.3176 & .1889
\end{tabular}


Entrepreneurship $\times$

Growth mindset - personality
.2010

.0947

2.1212

Dependence variable model (dependent variable: expected outcomes of startup)

\begin{tabular}{ccccc}
\hline Constant & 2.0734 & .1789 & 11.5910 & .0000 \\
\hline Entrepreneurship & .3204 & .0639 & 5.0135 & .0000 \\
\hline Entrepreneurial intention & .3576 & .0539 & 6.6318 & .0000 \\
\hline
\end{tabular}

The conditional effects of entrepreneurship according to the specific values of growth mindset for personality were as shown in Table 3. As a result, the conditional effects was significant in the range of growth mindset of -.6121 (M-1SD) to .6121 (M + 1SD) (Kamal, 2019); (Kangu et al., 2019).

The conditional effect of entrepreneurship was significant in the region where growth mindset value was higher than 1.0095. 93.6\% of the subjects showed significant moderating effect, where as $6.3 \%$ showed no significant conditional effect.

Table 3. Conditional effects of entrepreneurship at the value of growth mindset

\begin{tabular}{ccccccc}
\hline Growth mindset & Effect & $\mathrm{se}$ & $\mathrm{t}$ & $\mathrm{p}$ & LLCI $^{*}$ & ULCI $^{* * *}$ \\
\hline$-1 \mathrm{SD}(-.6121)$ & .3137 & .0909 & 3.4508 & .0007 & .1346 & .4927 \\
\hline $\mathrm{M}(.0000)$ & .4367 & .0695 & 6.2819 & .0000 & .2998 & .5736 \\
\hline$+1 \mathrm{SD}(.6121)$ & .5597 & .0902 & 6.2081 & .0000 & .3821 & .7373 \\
\hline
\end{tabular}

Significance area of conditional effects

\begin{tabular}{ccccccc}
\hline Growth mindset & Effect & se & $\mathrm{t}$ & $\mathrm{p}$ & LLCI $^{*}$ & ULCI $^{* *}$ \\
\hline-2.1130 & .0120 & .2125 & .0565 & .9550 & -.4065 & .4305 \\
\hline \multicolumn{1}{c}{.1 .0095} & .2338 & .1187 & 1.9695 & .0500 & .0000 & .4676 \\
\hline 1.8870 & .8159 & .1913 & 4.2655 & .0000 & .4392 & 1.1927 \\
\hline
\end{tabular}

*LLCI=The lower limit of the indirect effect within the $95 \%$ confidence interval

**ULCI $=$ The higher limit of the indirect effect within the $95 \%$ confidence interval

To confirm the shape based on the moderating effect of the growth mindset as shown in Figure 3, we examined the entrepreneurial intention with respect to entrepreneurship by dividing the growth variable into three groups of high, middle and low. Entrepreneurial intention with respect to entrepreneurship was higher in the order of low, middle, and high groups of growth mindset. Through these results, the effect of entrepreneurship on entrepreneurial intention shows that the higher the growth mindset, the higher the entrepreneurial intention. 


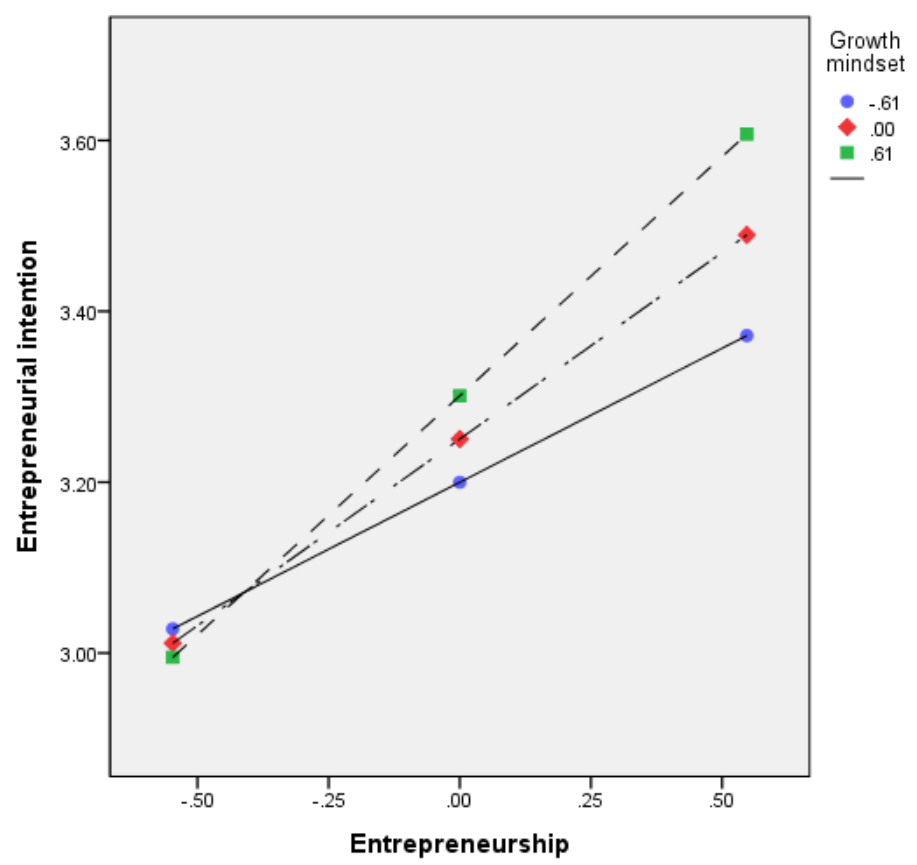

Figure 3. Moderating effects of growth mindset

Finally, the conditional indirect effects of the independent variable on the dependent variable with respect to the specific value of the moderating variable were as shown in Table 4. According to the analysis, the conditional indirect effects of the growth mindset on expected outcomes of startup (entrepreneurship $\rightarrow$ entrepreneurial intention $\rightarrow$ expected outcomes of startup) are significant in the growth mindset from -.6121 (M-1SD) to .6121 (M + 1SD). Therefore, the moderated mediation effect of the growth mindset was demonstrated.

Table 4. Result of moderated mediation effects of growth mindset

\begin{tabular}{ccccc}
\hline Conditional indirect effect & $\beta$ & Boot Se & LLCI $^{*}$ & ULCI $^{* *}$ \\
\hline $\mathrm{M}-1 \mathrm{SD}(-.6121)$ & .1122 & .0568 & .0171 & .2380 \\
\hline $\mathrm{M}(.0000)$ & .1562 & .0528 & .0647 & .2701 \\
\hline $\mathrm{M}+1 \mathrm{SD}(.6121)$ & .2001 & .0623 & .0902 & .3344 \\
\hline
\end{tabular}

Based on moderated mediation effect analysis, when entrepreneurship was high, entrepreneurial intention and expected outcomes of startup were high. Hence, growth mindset represents the moderated mediation effect by moderating the mediating effect of entrepreneurial intention.

\section{Conclusion}

This study confirmed the moderated moderation effect of growth mindset on the mediating effect of entrepreneurial intention in the relationship between entrepreneurship and expected outcomes of startup. The results showed that entrepreneurial intention mediated in the relationship between entrepreneurship and expected outcomes of startup, and in this relationship, growth mindset showed moderated mediation effect.

Based on the limitations of this study, follow up studies are needed. First, this study dealt with office workers within in Chungnam province. This includes the cases of satisfying the current working life, so future research needs to be conducted for those interested in start-up. Second, the study focused on variable relationships, but not in education and programs that promote entrepreneurship or growth mindset. Further research is needed to develop programs for promoting start-up.

In spite of these limitations, this study presented the growth mindset's moderated mediation effect on the relationship 
between entrepreneurship and expected outcomes of startup. Therefore, the findings of this study can be used to improve the expected outcomes of startup and provide opportunities to challenge various fields related to start-up.

\section{References}

Covin, J. G., \& Slevin, D. P. (1991). A conceptual model of entrepreneurship as firm behavior. Entrepreneurship Theory and Practice, 16(1), 7-26.

Crant, J. M. (1996). The proactive personality scale as a predictor of entrepreneurial intentions. Journal of Small Business Management, 34, 42-9.

Drucker, P. (2014). Innovation and entrepreneurship. New York: Routledge, p. 345.

Dweck, C. S. (2006). Mindset: The new psychology of success. New York: Ballantine Books, p. 320.

Heo, Y. J. (2018). A study on the effect of university students' work values and entrepreneurial self-efficacy on the entrepreneurial intention [dissertation]. [Gongju]: Kongju University, p. 71. Retrieved from http://www.riss.kr/link?id=T14693843

Jang, H. Y. (2018). The influence of employers' startup motives and entrepreneurship on the expected outcomes of startup: Moderated mediation effect of hope [dissertation]. [Seosan]: Hanseo University, p. 85. Retrieved from http://www.riss.kr/link?id=T14986056

Johar, M., Hidayat, M. T., \& Latif, R. A. (2017). An invention of baton dance? Exercise regime on obesity diagnosis among sedentary adults. International Journal of Asian Social Science, 7(1), 54-62.

Junwen, F., Gang, W., \& Yuchen, W. (2019). Impact of network finance development on inflation: evidence from Chinese market. The Economics and Finance Letters, 6(1), 67-77.

Kamal, M. A. (2019). Factors influencing human capital in ready made garments industry in Bangladesh. Journal of Social Economics Research, 6(1), 34-49.

Kang, S. B. (2012). Report on corporation performance influenced by entrepreneur's motive, entrepreneurship, and advanced preparation [dissertation]. [Seoul]: Chung-Ang University, p. 88. Retrieved from http://www.riss.kr/link?id=T12684182

Kangu, M., Kyule, A. K., \& Mutinda, B. (2019). Factors Influencing the Decision of the People of Kisii Town to Consume Domestic Tourism Products. Journal of Tourism Management Research, 6(1), 60-65.

Kim, S. S. (2018). A study on the effect of social support on the high degreed baby boomer's entrepreneurial opportunity competence: Focusing on mediating effect of entrepreneurial self-efficacy \& moderating effect of entrepreneurship [dissertation]. [Cheonan]: Hoseo University, p. 114. Retrieved from http://www.riss.kr/link?id=T14687511

Kim, W. J. (2016). The effects of entrepreneurship and strategic orientation on the firm performance: Moderated mediation effect of digital literacy and learning orientation. [dissertation]. [Seoul]: Chung-Ang University, p. 123. Retrieved from http://www.riss.kr/link?id=T14170677

Krueger, N. F., Reilly, M. D., \& Carsrud, A. L. (2000). Competing models of entrepreneurial intentions. Journal of Business Venturing, 15(5-6), 411-32. https://doi.org/10.1016/S0883-9026(98)00033-0

Ley, R., \& Timmons, B. H. (2013). Behavioral and psychological approaches to breathing disorders. New York: Springer Science \& Business Media, p. 320.

Lumpkin, G. T., \& Dess, G. G. (1996). Clarifying the entrepreneurial orientation construct and linking it to performance. Academy of management Review, 21(1), 135-72.

Molden, D. C., \& Dweck, C. S. (2006). Finding" meaning" in psychology: a lay theories approach to self-regulation, social perception, and social development. American Psychologist, 61(3), 192-203. https://doi.org/10.1037/0003-066X.61.3.192

Schumpeter, J. A. (1934). Change and the entrepreneur. Essays of JA Schumpeter, 4(23), 45-91.

Spencer, L. M., \& Spencer, P. S. M. (2008). Competence at Work models for superior performance. New Jersey: John Wiley \& Sons, p. 384. 